\title{
Lasting Syndrome of Depression Produced by Reduction in Serotonin Uptake during Postnatal Development: Evidence from Sleep, Stress, and Behavior
}

\author{
Daniela Popa ${ }^{1,2 *}$ Clément Léna, ${ }^{3 *}$ Chloé Alexandre, ${ }^{1,2}$ and Joëlle Adrien ${ }^{1,2}$ \\ ${ }^{1}$ Université Pierre et Marie Curie-Paris 6, Unité Mixte de Recherche S677, F-75013 Paris, France, ${ }^{2}$ Institut National de la Santé et de la Recherche Médicale \\ U677, Neuropsychopharmacologie, F-75013 Paris, France, and '3nité Mixte de Recherche 8544, École Normale Supérieure, F-75005 Paris, France
}

\begin{abstract}
Dysfunction of the serotonin system is implicated in sleep and emotional disorders. To test whether these impairments could arise during development, we studied the impact of early-life, transient versus genetic, permanent alterations of serotonin reuptake on sleep-wakefulness patterns, depression-related behavior, and associated physiological features. Here, we show that female mice treated neonatally with a highly selective serotonin reuptake inhibitor, escitalopram, exhibited signs of depression in the form of sleep anomalies, anhedonia, increased helplessness reversed by chronic antidepressant treatment, enhanced response to acute stress, and increased serotoninergic autoinhibitory feedback. This syndrome was not reproduced by treatment in naive adults but resembled the phenotype of mutant mice lacking the serotonin transporter, except that these exhibited decreased serotonin autoreceptor sensitivity and additional anxietylike behavior. Thus, alteration of serotonin reuptake during development, whether induced by external or genetic factors, causes a depressive syndrome lasting into adulthood. Such early-life impairments might predispose individuals to sleep and/or mood disorders.
\end{abstract}

Key words: 5-HT transporter; REM sleep; development; 5-HT1A autoreceptors; corticosterone; depression; anxiety; stress; knock-out mice

\section{Introduction}

The brain monoamine serotonin is involved in many functions, notably the regulation of sleep (Ursin, 2002) and mood, as demonstrated by the therapeutic efficacy of antidepressant treatment through the enhancement of serotoninergic neurotransmission (Blier and de Montigny, 1994) and by the association between the serotonin transporter polymorphism and susceptibility to depression (for review, see Levinson, 2006). There is growing evidence that the susceptibility to sleep disorders and depression could result, at least in part, from serotonin-dependent developmental alterations (Ansorge et al., 2004; Lattimore et al., 2005; Alexandre et al., 2006).

The monoaminergic systems are known to play a role in the maturation of the brain neural circuits. Pharmacological manipulations increasing brain monoamines during the first postnatal month in the rat produce permanent sleep and behavior depression-related deficits in adults (Mirmiran et al., 1981; Hi-

\footnotetext{
Received Feb. 10, 2007; revised Feb. 15, 2008; accepted Feb. 18, 2008.

This work was supported by the Institut National de la Santé et de la Recherche Médicale. D.P. and C.A. were supported by a grant from La Fondation pour la Recherche Médicale. We thank P. Venault and K. Yard for help with the behavioral tests, F. Saurini for help with the corticosterone assay, J. C. Alvarez for the escitalopram assay, and B. Barbour, P. Isope, and J. L. Bessereau for the critical reading of this manuscript.

${ }^{*} D$.P. and C.L. contributed equally to this work.

Correspondence should be addressed to either of the following: Dr. Daniela Popa, Center for Molecular and Behavioral Neuroscience, Aidekman Research Center, Rutgers State University, Newark Campus, 197 University Avenue, Newark, NJ 07102, E-mail: popa@ext.jussieu.fr; or Dr. Joëlle Adrien, Inserm U677, Faculté de Médecine Pitié-Salpêtrière, 90 Boulevard de I'Hospital, 75013 Paris, France, E-mail: adrien@ext.jussieu.fr.

DOI:10.1523/JNEUROSCI.4006-07.2008

Copyright $\odot 2008$ Society for Neuroscience $\quad 0270-6474 / 08 / 283546-09 \$ 15.00 / 0$
}

lakivi and Hilakivi, 1987; Vogel et al., 1990a; VelazquezMoctezuma and Diaz Ruiz, 1992; Frank and Heller, 1997). Today, the specific contribution of serotonin in these effects can be examined thanks to the advent of highly selective pharmacological tools, and of mice with targeted genetic disruption. Interestingly, whereas the developmental influence of serotonin on behavior has been assessed in tests of sexual activity (Maciag et al., 2006a,b), novelty-induced behavioral inhibition, and shock avoidance (Ansorge et al., 2008), that on sleep patterns has received only little attention (but see Alexandre et al., 2006). In contrast, the permanent increase in brain serotonin after the deletion of the serotonin transporter gene has been shown to lead to increased rapid eye movement sleep (REMS) (Wisor et al., 2003; Alexandre et al., 2006) and enhanced anxiety but less consistently to depression-like behavior (Holmes et al., 2002, 2003a; Lira et al., 2003; Ansorge et al., 2004; Kalueff et al., 2006; Zhao et al., 2006).

In humans, the depression syndrome is associated with behavioral/mood alterations and with a number of specific endophenotypes (Nestler et al., 2002; Hasler et al., 2004) that include specific sleep profile alterations with notably increased REMS as well as dysfunctions of the hypothalamicpituitary-adrenocortical (HPA) axis and of the serotoninergic system. The presence in animals of such trait-related features reinforces the etiological correspondence between animal models and the human disease (Hasler et al., 2004; Willner, 2005). In mice, depression-like behavioral alterations are studied in validated tests such as responses to an inescapable 
stress or measures of anhedonia (El Yacoubi et al., 2003). Here, we studied these paradigms in mice at 6-12 weeks after they had received a selective serotonin reuptake inhibitor (SSRI) treatment, either as neonates or as young adults, and in knock-out mice lacking the serotonin transporter, which therefore have a permanent increase in serotonin levels (Fabre et al., 2000). Because of the growing evidence that vulnerability to depression in rodents is, as in humans, larger in females than in males (Fava and Kendler, 2000; El Yacoubi et al., 2003), we performed our study in female animals. We report that early-life inactivation of the serotonin transporter yielded a wide spectrum of depression-related behavior and physiological alterations.

\section{Materials and Methods}

All procedures involving animals and their care were conducted in conformity with the institutional guidelines and in compliance with national and international laws and policies [Council Directive \#87-848 (October 19, 1987), Ministère de l'agriculture et de la forêt, Service vétérinaire de la santé et de la protection animale, permission \#75-125 to J.A.].

\section{Animals}

All experiments were performed on Swiss albino CD1 mice (Charles River Laboratories, Wilmington, MA). Mutant mice in which the serotonin transporter gene has been deleted were obtained originally from the colony of K. P. Lesch (University of Wuerzburg, Wuerzburg, Germany) (Bengel et al., 1998) and were successively backcrossed (F7) with Swiss albino CD1 mice. A behavioral comparison of treated wild-type (WT) and mutant (KO) mice was exclusively conducted on adult mice issued from heterozygous breeding. For the latter, genotyping was performed at $\sim 1$ month of age using PCR analysis of tissue samples from the tails. Mice were housed in a temperature-controlled room $\left(23 \pm 1^{\circ} \mathrm{C}\right)$ under a $12 \mathrm{~h}$ light/dark cycle (lights on from 7:00 A.M. to 7:00 P.M.), with food and water available ad libitum.

\section{Pharmacological treatments}

Drugs. The following drugs were used: escitalopram (a generous gift from Lundbeck, Copenhagen, Denmark), the most selective SSRI to date (Owens et al., 2001); fluoxetine (a generous gift from Lilly Research Laboratories, Indianapolis, IN), the most widely used antidepressant; and 8-hydroxy-2-(di-n-propylamino)tetralin (8-OH-DPAT) (Research Biochemicals International, Natick, MA), a selective agonist of 5- $\mathrm{HT}_{1 \mathrm{~A}}$ receptors.

Neonatal treatment. Mouse pups received escitalopram ( $10 \mathrm{mg} / \mathrm{kg}$, s.c., in $0.05 \mathrm{ml}$ of saline daily at 6:00 P.M.) or saline $(0.05 \mathrm{ml}$ under the same conditions) starting at postnatal day 5 (P5; the day of birth was counted as P0) and continuing daily for 2 weeks (Vogel et al., 1990a; Frank and Heller, 1997; Ansorge et al., 2004; Alexandre et al., 2006). The treatment assignment was randomized between saline and escitalopram, including across animals from the same litter (in which case pups were marked with China ink). A transient mild increase in the pups' weights was observed during escitalopram compared with saline treatment, but this difference was not present at adulthood. At $25 \mathrm{~d}$ of age, pups were weaned and separated by sex. The present work was performed on homozygous females of the WT and KO phenotypes referred to as "neoSSRI" for those treated with escitalopram, whereas all other animals were assigned to other studies. Investigations were started $6-8$ weeks after the end of treatment (i.e., in 2-month-old mice). A first set of animals was used for sleep studies (at baseline and after stress). A second set was used for corticosterone measurement in stress studies. A third set received 8-OHDPAT injections for investigating hypothermia. A fourth set issued from heterozygous breeding was used in the behavioral testing for baseline data in the following order: dark-light box, elevated plus maze (separated by at least $2 \mathrm{~d}$ ), sucrose preference, tail suspension test (TST), and forced swim test (FST; separated by $7 \mathrm{~d}$ ). Finally, WTneoSSRI animals belonging to this group underwent antidepressant treatment as described below. A fifth set of CD1 pups received the neonatal treatment and was killed at the end of the treatment for escitalopram assay (see below). The estrous cycle was generally not monitored, but its influence should be averaged out by the random sampling of the phases of the cycle across animals.

Adult treatment. For comparison with neonatal treatment, adult WT female mice (aged 2 months) received escitalopram or saline $(10 \mathrm{mg} / \mathrm{kg}$, s.c., in $0.1 \mathrm{ml}$ of saline daily at 6:00 P.M.) for 2 weeks. Investigations were started 6 weeks after the end of the treatment, and the tests were performed in parallel with the other groups.

Antidepressant treatment. For assessing additional depressive-like behavior in our model, fluoxetine was used as an antidepressant in adult WTneoSSRI animals. Fluoxetine was administered in the drinking water for $30 \mathrm{~d}(160 \mathrm{mg} / \mathrm{L}$ of water, corresponding to $18 \mathrm{mg} / \mathrm{kg} / \mathrm{d}$, changed weekly). For withdrawal, plain water was reintroduced for $12 \mathrm{~d}$. Paired control WTneoSSRI mice received plain water under the same conditions. The TST was performed before (baseline data) and at weekly intervals during and after treatment. The FST was conducted before fluoxetine treatment (baseline), as well as $2 \mathrm{~d}$ after the TST at the end of treatment, and after withdrawal.

Escitalopram assay. For this purpose, animals were decapitated $3 \mathrm{~h}$ after the last injection of the treatment, and their blood was collected, allowed to clot, and centrifuged at $1700 \times g$ for $25 \mathrm{~min}$ at $4^{\circ} \mathrm{C}$. Serum was then collected and stored at $-20^{\circ} \mathrm{C}$ until further analysis. Escitalopram was quantified by HPLC using the method described by Duverneuil et al. (2003). This dosage indicated plasma concentration of $105 \pm 9 \mathrm{ng} / \mathrm{ml}$ $(n=4)$.

\section{Sleep and wakefulness studies}

Surgery. Animals were implanted under deep ketamine/xylazine anesthesia (100 and $5 \mathrm{mg} / \mathrm{kg}$, i.p., respectively) with electrodes (made of enameled nichrome wire; $150 \mu \mathrm{m}$ in diameter) for polygraphic sleep monitoring (Lena et al., 2004; Popa et al., 2005). In brief, two EEG electrodes were positioned on the dura through holes made into the skull (2 $\mathrm{mm}$ lateral and $2 \mathrm{~mm}$ caudal to the bregma suture; and at midline, $1 \mathrm{~mm}$ caudal to the lambda), two EOG (electro-oculogram) electrodes were located subcutaneously on each side of the orbit, and EMG electrodes were inserted into the neck muscles. All electrodes were anchored to the skull with Superbond and acrylic cement and were soldered to a miniconnector also embedded in cement. The animals were transferred to individual cages $(20 \times 20 \times 30 \mathrm{~cm})$ and were left to recover for $10 \mathrm{~d}$ under standard conditions (see above). They were allowed to become accustomed to the recording cables for 2-3 d before recordings were started. For the study of spontaneous sleep-wake cycles, recordings were obtained for 96 consecutive hours. For stress experiments, recordings lasted for $24 \mathrm{~h}$ starting at 7:00 P.M.

Analysis. Polygraphic recordings were scored visually every $15 \mathrm{~s}$ epoch as wakefulness, REMS, and non-REMS (NREMS) following classical criteria (Popa et al., 2005), using the Somnologica software (Medcare, Reykjavik, Iceland). For analysis of the spontaneous sleepwake patterns, the durations of vigilance states for each animal were calculated for every hour for $96 \mathrm{~h}$ and averaged over $12 \mathrm{~h}$ cycles. The REMS latency was calculated as the delay between each sleep onset (that was preceded by at least $45 \mathrm{~s}$ of waking) and the next REMS episode lasting at least $30 \mathrm{~s}$. This delay was then averaged over all the sleep episodes occurring during the time period of interest (7:00 A.M. to 7:00 P.M., 7:00 P.M. to 7:00 A.M.).

Power spectrum analysis. The EEG signal was processed for power spectrum analysis as described previously (Alexandre et al., 2008). For each animal, the spectrum was estimated using the Welch's averaged periodogram taken over each sleep/wake state, after exclusion of the epochs at the transition between two different states.

\section{Immobilization stress}

Behavioral manipulation. At least $15 \mathrm{~d}$ after spontaneous sleep-wakefulness recording, mice were immobilized for $90 \mathrm{~min}$, from 5:30 P.M. to 7:00 P.M., by enclosure in a plastic mesh as described previously (Popa et al., 2006). At the end of this period, they were returned to their cage for $24 \mathrm{~h}$ sleep-wake monitoring. To use each mouse as its own control, it underwent a sham procedure $2 \mathrm{~d}$ before the immobilization stress experiment: the animal remained free in its home cage from 5:30 P.M. to 7:00 
P.M. and was connected to the recording cable a few minutes before the $24 \mathrm{~h}$ recording.

Serum corticosterone assay. Serum corticosterone levels were measured immediately after immobilization stress. For this purpose, animals were decapitated, and their blood was collected, allowed to clot, and centrifuged at $1700 \times g$ for $25 \mathrm{~min}$ at $4^{\circ} \mathrm{C}$. Serum was then collected and stored at $-20^{\circ} \mathrm{C}$ until further analysis. Corticosterone was quantified by radioimmunoassay using an ICN Pharmaceuticals (Orsay, France) kit.

\section{8-OH-DPAT-induced hypothermia}

Core body temperature was measured at an ambient temperature of $23 \pm 1^{\circ} \mathrm{C}$, by means of a thermocouple ( $1.5 \mathrm{~mm}$ in diameter; Betatherm, Galway, Ireland) inserted $1.5 \mathrm{~cm}$ into the rectum while gently holding the animal. Experiments started at 10:00 A.M. Basal temperature was measured $15 \mathrm{~min}$ before and just before the injection of $8-\mathrm{OH}-\mathrm{DPAT}(0.4 \mathrm{mg} / \mathrm{kg}$, s.c., dissolved in $0.1 \mathrm{ml}$ of saline). Afterward, measurements were made every $15 \mathrm{~min}$ for $1 \mathrm{~h}$ and then every hour until the temperature had returned to baseline.

\section{Behavioral tests}

Dark-light choice test. A box divided into bright (lit by a $75 \mathrm{~W}$ light bulb) and dark compartments of equal size $(21 \times 21 \times 26 \mathrm{~cm})$ was used. Mice were placed in the dark area, and the time spent in each compartment was measured for 5 min (Holmes et al., 2003b).

Elevated plus maze. Mice were placed on the center of the maze $(55 \mathrm{~cm}$ above the ground, central platform of $7 \times 7 \mathrm{~cm}$, alleys of $30 \times 7 \mathrm{~cm}$, two opposite alleys with $17 \mathrm{~cm}$ high walls), facing one closed arm, and were allowed to explore the maze for $5 \mathrm{~min}$ (Lister, 1987). Movements were recorded using a video camera positioned above the maze. The number of entries and time spent in the open and closed arms, as well as the number of rears, were measured.

Sucrose preference test. The consumption of water was assessed for $2 \mathrm{~d}$ before the test. The sucrose preference test was performed during the following $4 \mathrm{~d}$, with a free choice between two droppers of $15 \mathrm{ml}$ placed in each cage, one containing sucrose (2\% in water) and the other containing water. To eliminate potential side preferences, the position of the droppers was switched after $2 \mathrm{~d}$. The consumption of water and sucrose solution was assessed daily. The preference for sucrose was calculated as the volume of sucrose solution consumed relative to the total volume of liquid consumed (Kalueff et al., 2006).

TST. The TST was performed with a computerized device (Bioseb, Bordeaux, France) according to a method described previously (El Yacoubi et al., 2003; Alexandre et al., 2006). Briefly, mice were suspended by the tail with adhesive tape to a hook connected to a strain gauge. The latter transmitted movements to a computer that calculated the total duration of immobility during a 6 min test.

FST. The FST was applied as described by Porsolt et al. (1977): mice were placed individually into glass cylinders (height, $25 \mathrm{~cm}$; diameter, 10 $\mathrm{cm}$ ) containing water at a depth of $10 \mathrm{~cm}$, maintained at $23-25^{\circ} \mathrm{C}$. Animals were tested for a total of $6 \mathrm{~min}$. The time of immobility was assessed during the last $4 \mathrm{~min}$ (i.e., after $2 \mathrm{~min}$ of habituation).

\section{Statistics}

Values in the text and figures are mean \pm SEM. ANOVA $F$ values indicated in the text correspond to group effect, unless stated otherwise. Repeated-measures ANOVA was performed in sleep studies to assess the effect of 8-OH-DPAT and fluoxetine treatments [with time, and treatment when required, as repeated factor(s)]. $p$ values were obtained from Tukey's honestly significant difference tests in the case of group comparisons. Paired $t$ tests were used for repeated measures in post hoc tests, and $p$ values were adjusted by applying the (post hoc) Holm-Bonferroni procedure.

\section{Results}

To assess the impact of increased serotonin levels during development on adult sleep and emotional function, we examined the characteristics of WT mice that had received a transient serotonin transporter inactivation by neonatal treatment with the SSRI escitalopram (WTneoSSRI), compared with control neonatal saline treatment (WT). Mutant mice lacking the serotonin transporter gene (KO) were used to investigate, under the same experimental conditions, the effect of permanent serotonin transporter inactivation. Under baseline conditions, all groups of mice exhibited classical hypnograms (Fig. $1 A$ ), and the same diurnal rhythm of NREMS and wakefulness, with increased NREMS duration during the light phase (data not shown), and no rhythm for REMS (Fig. $1 B$ ). These characteristics are typical of the CD1 strain of mice (Alexandre et al., 2006). 


\section{Sleep abnormalities}

REMS

Changes in REMS latency, total duration, and number of rapid eye movements are robust and specific features of sleep in depressed patients (Benca, 2000). In the same manner, REMS was profoundly modified in mice with a history of serotonin transporter function impairment. REMS total duration was increased in WTneoSSRI and KO mice compared with WT during both the light and the dark phases $\left(F_{(2,21)}=29.47 ; p<0.0001\right)$ (Fig. $1 B$ ). This enhancement was accompanied by an increase in the number of REMS episodes $\left(F_{(2,21)}=21.23 ; p<0.0001\right)$ and by a decrease in REMS latency $\left(F_{(2,21)}=12.50 ; p=0.0003\right)$. The frequency of the theta rhythm during REMS was also different across groups $\left(F_{(2,21)}=4.03 ; p=0.03\right)$, with a significant acceleration in KO compared with WT mice (peak frequency, $7.51 \pm$ 0.17 vs $7.10 \pm 0.07 \mathrm{~Hz}$; $p<0.05$ ); WTneoSSRI mice exhibited an intermediate frequency $(7.27 \pm 0.07 \mathrm{~Hz})$. Therefore, both the transient and the permanent inactivation of serotonin reuptake affect adult REMS characteristics.

\section{NREMS}

The three groups of mice exhibited the same total duration of $\operatorname{NREMS~}\left(F_{(2,21)}=0.39 ; p=0.68\right)$ (Fig. $\left.1 C\right)$, with a pattern similar in WTneoSSRI and WT mice but different in KO mice, which showed an increased number and decreased mean duration of NREMS episodes $\left(F_{(2,21)}=11.83, p=0.0004\right.$, and $F_{(2,21)}=6.98$, $p=0.005$, respectively) (Fig. $1 C$ ), indicating an enhanced fragmentation of NREMS.

Finally, we verified that the effects of neonatal SSRI treatment on sleep were attributable to specific action at the serotonin transporter using mutant mice lacking the serotonin transporter. As expected from their lack of serotonin reuptake capacity, mutants that received early-life escitalopram treatment $(n=7)$ exhibited the same sleep-wake characteristics as the KO mice (that received saline during the same postnatal period) (supplemental Fig. 1, available at www.jneurosci.org as supplemental material).

In summary, the transient neonatal and permanent inactivation of the serotonin transporter increased REMS propensity in a manner consistent with clinical observations in depressed patients, but opposite to the effect of an acute SSRI injection (Monaca et al., 2003). No significant quantitative changes in NREMS were found after these treatments, except for a discreet fragmentation in $\mathrm{KO}$ mice, which might possibly relate to their anxietylike profile (Fuller et al., 1997).

\section{Immobilization stress}

Functional impairments of the HPA axis have been found in a large number of depressive patients (Gillespie and Nemeroff, 2005), using the dexamethasone suppression test that challenges the negative feedback on the HPA system. This feedback is mediated by glucocorticoid receptors in the hippocampus, the activation of which lowers stress hormones to normal levels after an acute stress (Sapolsky et al., 1984). We investigated the response of this system in mice using an acute immobilization stress. In rodents, stress-elicited activation of the HPA system triggers a delayed increase in REMS, related to the serum corticosterone level (Marinesco et al., 1999).

After 90 min of immobilization, WT and WTneoSSRI mice exhibited a significant increase in total REMS duration on the following day, whereas $\mathrm{KO}$ mice showed no change (Fig. $2 \mathrm{~B}$ ) (interaction group $\times$ effect of stress: $F_{(2,98)}=6.06, p=0.003$ ). No differences were observed in the duration of the other vigilance states. The absence of the REMS rebound in KO mice sug-
A

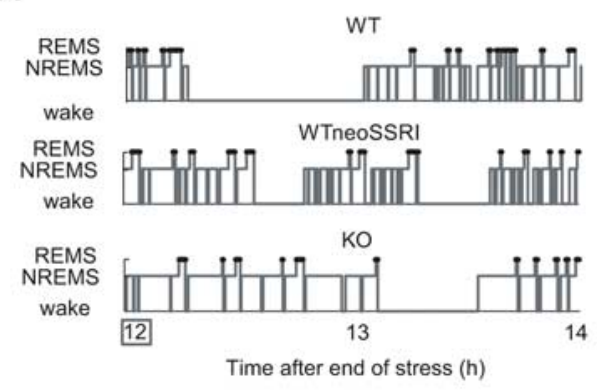

B

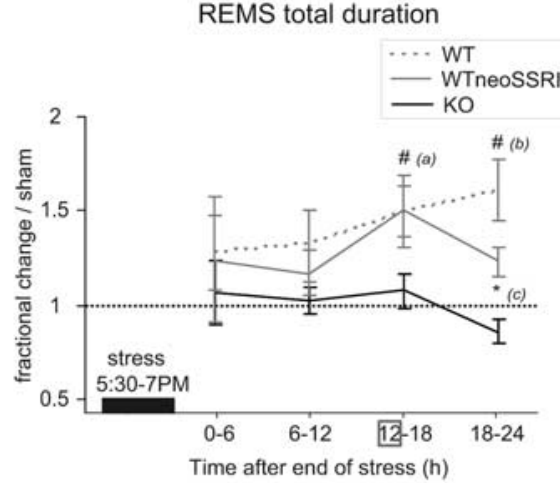

C

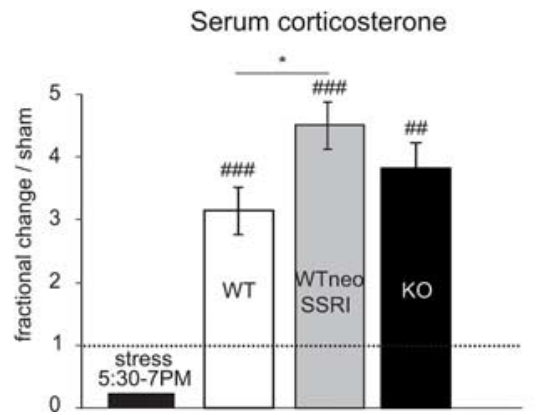

Figure 2. Alteration in sleep patterns and hormonal response after an acute stress in the mouse. $\boldsymbol{A}$, Examples of hypnograms 12-14 h after stress (for the time period 7:00 -9:00 A.M.) in mice from the same groups as in Figure 1. $\boldsymbol{B}$, Time course of REMS duration after stress $(90 \mathrm{~min}$ of immobilization). Results are expressed as a fraction of REMS duration in the sham condition for WT (dashed line; $n=5$ ), WTneoSSRI (thin line; $n=5$ ), and KO (bold line; $n=7$ ) groups. Significance labels are as follows: (a), WT and WTneoSSRI significantly different from sham condition; (b), WT significantly different from sham condition; (c), WT and WTneoSSRI significantly different from KO. C, Serum corticosterone levels immediately after the end of the acute stress are expressed as a fraction of average serum corticosterone levels in sham conditions. Group sizes are as follows: WT: sham, $n=10$; stress, $n=10$; WTneoSSRl: sham, $n=8$; stress, $n=10 ; \mathrm{KO}$ : sham, $n=7$; stress, $n=7$. Values plotted are mean \pm SEM ${ }^{*} p<0.05$, significant difference between groups; ${ }^{\#} p<0.05 ;{ }^{\# \#} p<0.01 ;{ }^{\# \# \#} p<0.001$, significantly different from sham condition.

gested a deficit in HPA homeostasis (Boutrel et al., 2002; Lena et al., 2004; Popa et al., 2006) in these mice. To test directly the functionality of the HPA axis, we also measured plasma corticosterone levels in the three groups of mice immediately after stress. We found no difference between the basal level of corticosterone, but the groups differed in their hormonal response to stress (Fig. $2 C$ ) (interaction group $\times$ effect of stress: $F_{(3,34)}=3.83, p=0.02$ ), with the WTneoSSRI mice exhibiting a larger increase in corticosterone levels than WT mice ( $p=0.03)$ and the KO mice corticosterone increase falling between the two groups.

Therefore, the sleep response to an acute stress, which requires a functional HPA homeostasis, was impaired after the permanent deletion of the serotonin transporter gene, whereas the activation 
A

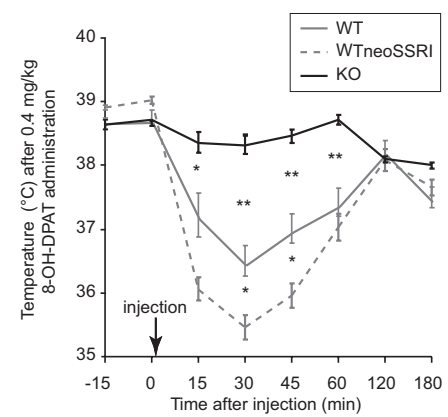

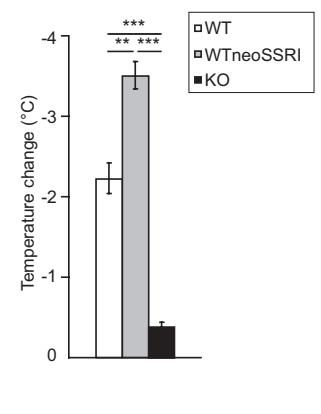

Figure 3. Effect of $5-\mathrm{HT}_{1 \mathrm{~A}}$ receptor activation on core temperature. The time course of temperature $(\boldsymbol{A})$ and maximal hypothermia $(\boldsymbol{B})$ after $8-\mathrm{OH}-\mathrm{DPAT}$ injection $(0.4 \mathrm{mg} / \mathrm{kg}$, s.c.) is shown. The group labeling is as in Figure 1 (WT, $n=5 ;$ WTneoSSRI, $n=7 ; \mathrm{KO}, n=6$ ). Values plotted are mean \pm SEM, and significance is tested against the WT group. WTneoSSRI and KO are significantly different $(p<0.001)$ for the times $15-60$ min. ${ }^{*} p<0.05 ;{ }^{* *} p<0.01$; ${ }^{* * *} p<0.001$.

of the HPA axis was exaggerated after the transient inactivation of the transporter during development.

\section{Body temperature}

$5-\mathrm{HT}_{1 \mathrm{~A}}$ autoreceptors in raphe serotoninergic neurons participate in the control of central serotonin neurotransmission by mediating a negative feedback regulation of serotonin neuron firing. The functional desensitization of these autoreceptors is thought to play a key role in the therapeutic action of antidepressants (Pineyro and Blier, 1999), whereas their upregulation could be related to core symptoms of depression (Stockmeier et al., 1998; El Yacoubi et al., 2003). In the mouse, injection of the $5-\mathrm{HT}_{1 \mathrm{~A}}$ agonist $8-\mathrm{OH}-\mathrm{DPAT}$ produces a transient hypothermia that is essentially mediated by $5-\mathrm{HT}_{1 \mathrm{~A}}$ autoreceptors (Goodwin et al., 1985). Thus, in mice, the degree of hypothermia induced by 8-OH-DPAT injection has been validated as a measure of the functional status of these autoreceptors (Bouali et al., 2003; El Yacoubi et al., 2003; Alexandre et al., 2006). Systemic injection of 8-OH-DPAT $(0.4 \mathrm{mg} / \mathrm{kg}$, s.c.) induced a greater hypothermia in WTneoSSRI mice than in WT mice, indicating a hypersensitivity of 5- $\mathrm{HT}_{1 \mathrm{~A}}$ autoreceptors in the former group (Fig. 3). In contrast, $\mathrm{KO}$ mice failed to develop hypothermia after injection of $8-\mathrm{OH}-$ DPAT, indicating a loss of $5-\mathrm{HT}_{1 \mathrm{~A}}$ autoreceptor sensitivity in mutants (time $\times$ group interaction during the hour after injection: $F_{(6,45)}=61.55, p<0.0001$; time $\times$ group effect for maximal temperature decrease: $\left.F_{(2,15)}=116.22, p<0.0001\right)$ (Fig. 3). The enhanced 8-OH-DPAT-induced hypothermia in WTneoSSRI mice was specifically attributable to neonatal alteration of the serotonin reuptake, because a separate group of mice lacking the serotonin transporter $(n=7)$ that received neonatal treatment with escitalopram under the same conditions showed no potentiation of hypothermia (supplemental Fig. 1, available at www. jneurosci.org as supplemental material).

Thus, the transient neonatal and permanent inactivation of the serotonin transporter differentially affected the $5-\mathrm{HT}_{1 \mathrm{~A}}$ autoreceptor-mediated response. Only the neonatal treatment was found to produce hypersensitivity of these autoreceptors, in support of a depressive-like endophenotype (El Yacoubi et al., 2003).

\section{Anxiety-related behaviors}

Anxiety was assessed in the light-dark choice test and in the elevated-plus maze (Fig. 4A), in which a decreased duration of
A

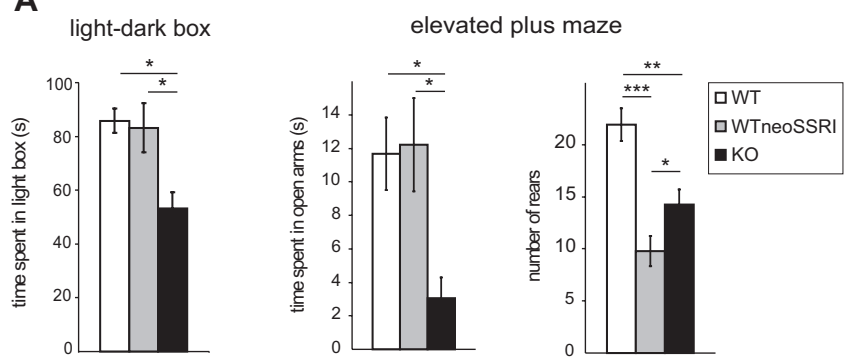

B

sucrose preference

tail suspension test

forced swim test
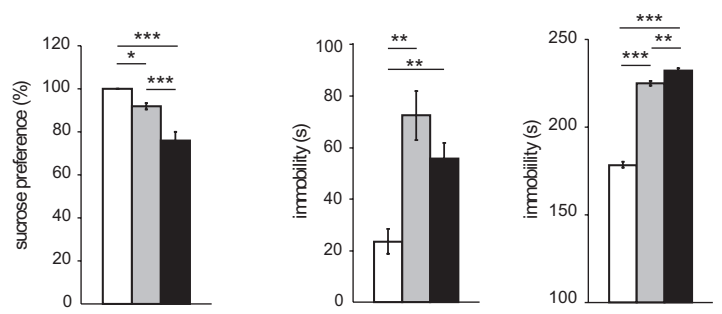

Figure 4. Anxiety- and depression-related behavior in adult mice after transient neonatal and permanent genetic inactivation of the serotonin transporter. The group labeling is as in Figure 1 (WT, $n=12-14$; WTneoSSRI, $n=24-26 ; \mathrm{K} 0, n=16$ ). $\boldsymbol{A}$, Anxiety, measured in the dark-light box test, is expressed as time spent in the (anxiogenic) light box (for a test duration of $5 \mathrm{~min}$ ). The elevated-plus maze graph displays the time spent in the (anxiogenic) open arm (left), for a test duration of $5 \mathrm{~min}$, and the number of rears (reflecting the exploratory behavior) during the entire test (right). $\boldsymbol{B}$, Depression-like behavior: anhedonia in the sucrose preference test (left). Sucrose solution consumption is reported as a percentage of the total liquid consumption. The immobility total duration (in seconds) in the TST (middle) and the FST (right) is shown. Values plotted are mean \pm SEM $^{*} p<0.05 ;{ }^{* *} p<0.01 ;{ }^{* * *} p<0.001$, significant difference between groups.

time spent in the light box or open arms reflects anxiety. WTneoSSRI mice did not differ from WT mice, whereas KO mice spent less time in the light box and in open arms $\left(F_{(2,51)}=3.99\right.$, $p=0.025$, and $F_{(2,49)}=4.15, p=0.022$, respectively) compared with other groups, indicating an enhanced anxiety phenotype in mutants. WTneoSSRI and KO mice also exhibited a reduced number of rears (Fig. $4 A$ ) and total arm entries (data not shown; $F_{(2,49)}=14.14, p<0.0001$, and $F_{(2,49)}=5.12, p=0.009$, respectively), which reflect a general reduction in exploratory and locomotor activity. Thus, KO but not WTneoSSRI mice exhibited increased anxiety compared with WT controls.

\section{Depression-related behaviors}

The presence of a depressive behavioral phenotype was assessed using three different tests (Fig. $4 B$ ). A test for anhedonia, the preferential consumption of a sucrose solution, assesses the loss of appetitive motivation, a core symptom of depression. Total fluid intake was the same in all groups $(\sim 4.3 \mathrm{ml} / \mathrm{d})$. Sucrose preference and sucrose intake (in g/kg/d: WT, $2.81 \pm 0.09$; WTneoSSRI, $2.68 \pm 0.07 ; \mathrm{KO}, 2.27 \pm 0.16)$ were significantly lower in WTneoSSRI and $\mathrm{KO}$ mice compared with WT mice $\left(F_{(2,49)}=\right.$ 20.75, $p<0.0001$, and $F_{(2,49)}=4.76, p=0.013$, respectively), with the WTneoSSRI mice having an intermediate profile between the two other groups. The TST and FST are two paradigms of "behavioral despair" in the face of an inescapable stress, with the periods of immobility used to characterize depression-like behavior (El Yacoubi et al., 2003). The reduction in immobility in these tests is also used to identify potential antidepressant properties of compounds (Porsolt et al., 1978; Steru et al., 1985). In these tests, WTneoSSRI and KO mice exhibited a longer total 


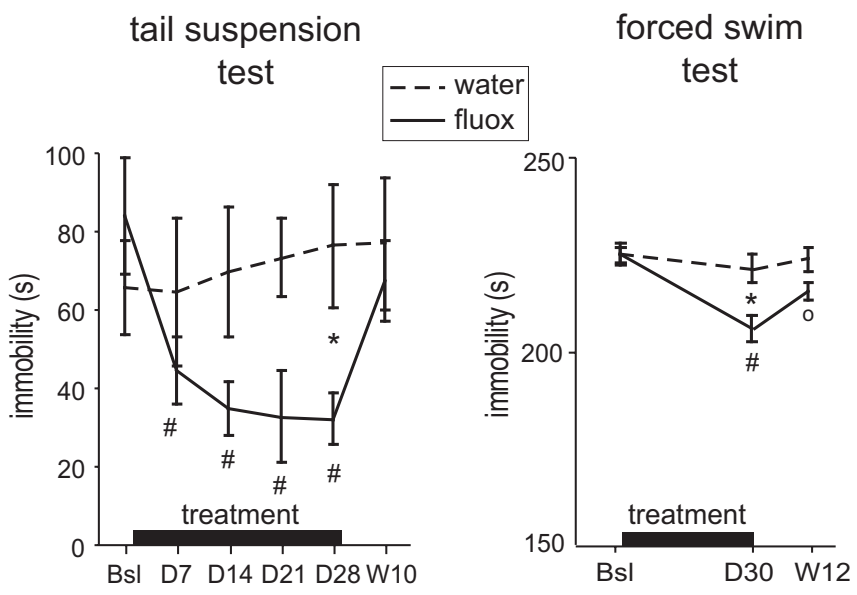

Figure 5. Effect of chronic fluoxetine treatment in adult WTneoSSRI mice. Immobility total duration is measured in WTneoSSRI mice receiving fluoxetine in drinking water (fluox; $n=14$ ) or plain water (water; $n=9$ ) in their bottle; the $x$-axis represents baseline (Bsl) tests and the days of test sessions (D7-D30) or of withdrawal (W10-W12). Values plotted are mean \pm SEM. ${ }^{*} p<0.05$, significant difference between groups; ${ }^{*} p<0.05$, within-group significant difference with Bsl (paired test); ${ }^{\circ} p<0.05$, within-group significant difference from Bsl and D30.

duration of immobility than WT mice (TST: $F_{(2,53)}=7.90, p<$ 0.0001; FST: $\left.F_{(2,49)}=253.32, p<0.0001\right)$. These results indicate a behavioral depression-like phenotype in WTneoSSRI and $\mathrm{KO}$ mice.

Then, to verify that this phenotype in WTneoSSRI mice was sensitive to antidepressant treatment, we treated these animals with fluoxetine $(18 \mathrm{mg} / \mathrm{kg} / \mathrm{d}$ in drinking water for $30 \mathrm{~d})$ and compared their immobility to paired controls (that drank plain water). Chronic administration of the antidepressant fluoxetine in adult WTneoSSRI mice reversibly reduced the total duration of immobility in both the TST $\left(F_{(1,63)}=7.15 ; p=0.014\right)$ and the FST $\left(F_{(1,22)}=9.31 ; p=0.006\right)$ (Fig. 5). The effect of fluoxetine treatment on scores in the TST slowly developed over 1 month of treatment, a time course that is classically observed for the beneficial effect of antidepressants in patients. Interestingly, control WTneoSSRI animals (that received plain water in their bottle) showed the same scores of immobility all along the treatment despite the weekly repeated TST sessions. This indicates, in agreement with the results of El Yacoubi et al. (2003) in the same strain of mice, that the weakly repetition of tail suspension testing (Wellman et al., 2007) did not represent significant chronic stressors in CD1 mice.

Overall, these results indicate dissociation between depression- and anxiety-related behaviors. A transient block of serotonin transporter during development induced a depressionlike behavioral phenotype without an anxiety-like component, whereas the genetic deletion of the serotonin transporter produced both depression- and anxiety-like behaviors in adults.

\section{Chronic SSRI treatment in adult mice}

To assess whether the effects observed above were specific to early-life SSRI treatment, we performed the same treatment at adulthood (i.e., in 8-week-old WT mice). In these adult animals, a 2 week escitalopram treatment induced no long-term (assessed 6 weeks after the end of treatment) modifications of sleep, immediate HPA system activation after acute stress, 8-OH-DPATinduced hypothermia, or behavior in the sucrose preference test, TST, and FST (Fig. 6). Therefore, the changes after the neonatal escitalopram treatment reported above likely correspond to an alteration of brain circuits during a critical phase of development, rather than to long-lasting effects of the drug.

\section{Discussion}

In this study, we found that the transient pharmacological block of the serotonin transporter during early postnatal life induced a lasting syndrome of depression. This syndrome was evident at adulthood through a specific increase in REMS, altered sleep, and corticosterone responses to an acute stress, increased serotoninergic autoinhibitory feedback, and depression-like behavior that was reversed by chronic antidepressant treatment. Similar symptoms were found in mice with genetic inactivation of the transporter, which also showed the sleep and behavioral syndrome, but with increased anxiety and decreased 5-HT $\mathrm{HA}_{1 \mathrm{~A}}$ autoreceptor function. Our results demonstrate that alterations of serotonin reuptake, and therefore of brain serotonin levels, during a critical period of early life produce both biological and behavioral symptoms of depression.

\section{Critical period in the maturation of sleep and behavior}

The neonatal (P5-P19) treatment of mice with the SSRI escitalopram produced depressive-like sleep, behavior, and various biological phenotypes, but these effects were not observed after a treatment of the same duration performed at 2 months of age. This finding confirms and extends previous studies (Vogel et al., 1990a,b; Frank and Heller, 1997; Ansorge et al., 2004, 2008; Alexandre et al., 2006; Maciag et al., 2006b) and argues strongly for the existence of a critical period in the serotoninergic developmental control of neural circuits involved in REMS and depression. Conversely, the inhibition of serotonin synthesis or the block of $5-\mathrm{HT}_{1 \mathrm{~A}}$ receptors during the same neonatal period in mutant mice lacking the serotonin transporter reversed the REMS anomalies found in these mutants (Alexandre et al., 2006). Furthermore, the same developmental period was identified in mice with a conditional deletion of the $5-\mathrm{HT}_{1 \mathrm{~A}}$ receptor gene for the establishment of the behavioral anxious phenotype (Gross et al., 2002). Altogether, these results indicate that sleep homeostasis and anxio-depressive-like behavior in adult mice are directly related to early postnatal life changes in serotonin levels possibly acting via $5-\mathrm{HT}_{1 \mathrm{~A}}$ receptors.

\section{REMS after genetic and neonatal increase in serotonin}

Depressed patients show a high prevalence of increased REMS duration and decreased REMS latency (Benca, 2000). We found the same anomalies in both WT mice that had received a neonatal escitalopram treatment and KO mice. Such changes in REMS are also found in several rodent models of depression (Shiromani et al., 1988; Vogel et al., 1990a; Adrien et al., 1991; Dugovic et al., 1999; Popa et al., 2006) and in mutant mice that lack the serotonin transporter (Wisor et al., 2003; Alexandre et al., 2006, this study). In contrast, acute serotonin transporter inactivation, which induces enhancement of extracellular serotonin levels in the brain (Evrard et al., 2002), exerts an inhibitory action on REMS generation (Ursin, 2002). Thus, the mechanisms underlying REMS enhancement in WTneoSSRI and KO mice are probably mediated by a developmental role of serotonin (Gaspar et al., 2003), notably the construction of neural circuits controlling REMS (Alexandre et al., 2006).

\section{Depression- and anxiety-like behaviors}

Depression and anxiety are related pathologies in humans. Although increased anxiety has been observed in most studies of mutant mice lacking the serotonin transporter (for review, see 
Murphy and Lesch, 2008), behavioral tests of depression have yielded less consistent results (Holmes et al., 2002; Lira et al., 2003; Kalueff et al., 2006; Zhao et al., 2006). In our study, both KO and WTneoSSRI mice exhibited a depression-like behavior with reduced sucrose preference, interpreted as anhedonia, and increased immobility in TST and FST paradigms, interpreted as behavioral despair (El Yacoubi et al., 2003). However, signs of anxiety in two conflict tests, the elevated-plus maze and the dark-light box test, were absent in mice that had received a neonatal escitalopram treatment. This is similar to data observed after a neonatal treatment with other SSRIs (Hansen et al., 1997; Maciag et al., 2006a,b). Interestingly, the rapidly metabolized citalopram was less efficient than slowly metabolized fluoxetine (Geczy et al., 2000; Kugelberg et al., 2003; Ansorge et al., 2008) to induce deficits in novelty-induced tests of behavioral inhibition (which are sensitive to mild increases in anxiety) (Ansorge et al. 2008). This suggests that a stronger or sustained increase in brain serotonin compared with that induced by escitalopram may be required to produce anxiety (see also Gross et al., 2002).

Our work provides unique evidence of clear-cut, depression-like behavior comprising anhedonia and deficits in TST and FST not only in WT mice treated neonatally with escitalopram but in mutant mice lacking the serotonin transporter. Such finding in the latter mutants is discrepant with data in the literature (Holmes et al., 2002; Lira et al., 2003; Kalueff et al., 2006; Zhao et al., 2006). This may result first from the genetic background used in our study (CD1 rather than an inbred 129 or C57BL/6 strain as used in most studies). Indeed, the CD1 strain has already been used to generate a genetic model of depression (El Yacoubi et al., 2003). Second, the present study was performed in females. The prevalence rate of depression is much higher in women than in men (Fava and Kendler, 2000), and SSRIs are often more efficient in woman (Kornstein et al., 2000). Similarly, females were found to be more affected than males with regard to behavior in the genetic model of depression derived from CD1 mice (El Yacoubi et al., 2003) and with regard to serotoninergic neurotransmission in serotonin transporter-deficient mice of the same strain (Bouali et al., 2003). It would thus be interesting to compare the effect of neonatal treatments in CD1 males and females mice. Third, the fact that $\mathrm{KO}$ mice had received neonatal saline injections (like WT control mice) might be responsible for some behavioral differences from naive mice of this mutant strain. It thus appears that unknown genetic or epigenetic factors, such as sexual hormones (Bouali et al., 2003), also contribute to shape the phenotype resulting from serotonin transporter gene deletion.

\section{Stress control circuits}

A weakening of the negative feedback loop has been found in animal models of depression (Prathiba et al., 1998; Dugovic et al., 1999; Ladd et al., 2004; Popa et al., 2006) and accords with findings (Wellman et al., 2007; present study) that neonatal impair-
B tail suspension test
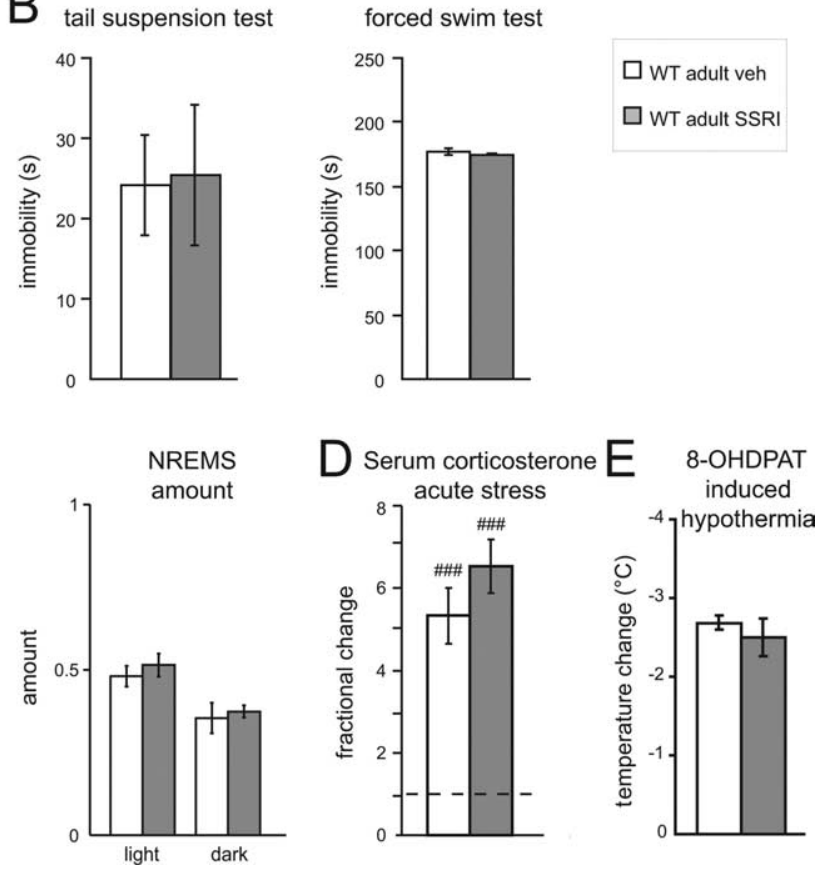

Figure 6. Absence of long-term effect of a 2 week SSRI treatment with escitalopram performed at adulthood. The tests were started 6 weeks after the end of treatment. veh, Vehicle. $A$, Sucrose preference expressed as a fraction of total liquid intake (WT adult veh, $n=7$; WT adult SSRI, $n=8$ ). $\boldsymbol{B}$, Immobility time in the TST (WT adult veh, $n=11$; WT adult SSRI, $n=12$ ) and FST

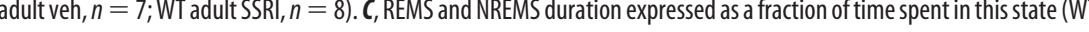
Maximal hypothermia after 8-OH-DPAT injection $(0.4 \mathrm{mg} / \mathrm{kg}$, S.c.; WT adult veh, $n=5$; WT adult SSRI, $n=6)$. Values plotted are

ment of the serotonin transporter or its genetic deletion increases the HPA axis response. This phenomenon is most probably accounted for by developmental alterations of corticolimbic pathways controlling the response to stress (for review, see Hariri and Holmes, 2006; Wellman et al., 2007). In the same manner in humans, a polymorphism in the serotonin transporter gene might produce an increased vulnerability to stress-induced depression (Caspi et al., 2003).

\section{Serotonin autoreceptors of the $5-\mathrm{HT}_{1 \mathrm{~A}}$ subtype}

We found that transient neonatal block and permanent disruption of serotonin transporter function, respectively, increased and decreased 5- $\mathrm{HT}_{1 \mathrm{~A}}$ autoreceptor function. Increased 5- $\mathrm{HT}_{1 \mathrm{~A}}$ autoreceptor density/sensitivity is sometimes observed in depressed patients (Stockmeier et al., 1998; Cowen, 2000; Arango et al., 2001), is found in validated animal models of depression (Overstreet, 2002; El Yacoubi et al., 2003), and is observed for the first time here after neonatal treatment with SSRI. By enhancing serotoninergic autoinhibition (Pineyro and Blier, 1999), it likely contributes to the deficit in serotoninergic transmission found in depression models (Overstreet, 2002; El Yacoubi et al., 2003). This contrasts with the desensitization of the 5- $\mathrm{HT}_{1 \mathrm{~A}}$ autoreceptors in mutant mice with a deletion of the serotonin transporter gene (Fabre et al., 2000; Bouali et al., 2003; Li et al., 2004; Alexandre et al., 2006; present study). Thus, the adult 5- $\mathrm{HT}_{1 \mathrm{~A}}$ autoreceptor sensitivity is partly determined by the state of serotoninergic function during early life, as also observed for other determinants of the serotoninergic transmission (Hansen and Mikkelsen, 1998; Maciag et al., 2006a). 
In conclusion, our data show the presence of a critical period for serotonin action on neural circuits controlling sleep, behavior, and the biological signs of depression. The striking resemblance between these paradigms after neonatal SSRI treatment and serotonin transporter gene inactivation indicates that the sleep- and depression-like phenotypes are likely acquired during development. Our study may help to define a paradigm to analyze how serotonin-dependent developmental mechanisms lead to depression endophenotypes in adults. Ample evidence from animal studies indicates the risks of monoamine manipulation during development (Maciag et al., 2006a). Here, we found that the persistent alterations of sleep and behavior were produced by neonatal exposure to plasma escitalopram concentration similar to that found in humans (Maciag et al., 2006a). Although the impact at adult age of perinatal exposure to SSRI remains to be assessed in humans, the present study reinforces the idea that exposure to SSRIs during development warrants caution. Finally, early-life treatments in animals can be used to examine whether persistent alterations of sleep- and depression-like behavior, because of genetic causes, may be prevented by correcting brain serotonin levels (Ishiwata et al., 2005) or anomalous receptor activation (Alexandre et al., 2006) during development. The use of such models should thus help understand, and maybe correct, the persistent alterations resulting from anomalous serotonin concentrations during development.

\section{References}

Adrien J, Dugovic C, Martin P (1991) Sleep-wakefulness patterns in the helpless rat. Physiol Behav 49:257-262.

Alexandre C, Popa D, Fabre V, Bouali S, Venault P, Lesch KP, Hamon M, Adrien J (2006) Early life blockade of 5-hydroxytryptamine 1A receptors normalizes sleep and depression-like behavior in adult knock-out mice lacking the serotonin transporter. J Neurosci 26:5554-5564.

Alexandre C, Dordal A, Aixendri R, Guzman A, Hamon M, Adrien J (2008) Sleep-stabilizing effects of E-6199, compared to Zopiclone, Zolpidem and THIP in mice. Sleep 32:259-270.

Ansorge MS, Zhou M, Lira A, Hen R, Gingrich JA (2004) Early-life blockade of the 5-HT transporter alters emotional behavior in adult mice. Science 306:879-881.

Ansorge MS, Morelli E, Gingrich JA (2008) Inhibition of serotonin but not norepinephrine transport during development produces delayed, persistent perturbations of emotional behaviors in mice. J Neurosci 28:199-207.

Arango V, Underwood MD, Boldrini M, Tamir H, Kassir SA, Hsiung S, Chen JJ, Mann JJ (2001) Serotonin 1A receptors, serotonin transporter binding and serotonin transporter mRNA expression in the brainstem of depressed suicide victims. Neuropsychopharmacology 25:892-903.

Benca R (2000) Mood disorders. In: Principles and practice of sleep medicine (Kryger M, Roth T, Dement W, eds), pp 1140-1158. Philadelphia: Saunders.

Bengel D, Murphy DL, Andrews AM, Wichems CH, Feltner D, Heils A, Mossner R, Westphal H, Lesch KP (1998) Altered brain serotonin homeostasis and locomotor insensitivity to 3, 4-methylenedioxymethamphetamine ("Ecstasy") in serotonin transporter-deficient mice. Mol Pharmacol 53:649-655.

Blier P, de Montigny C (1994) Current advances and trends in the treatment of depression. Trends Pharmacol Sci 15:220-226.

Bouali S, Evrard A, Chastanet M, Lesch KP, Hamon M, Adrien J (2003) Sex hormone-dependent desensitization of 5-HT1A autoreceptors in knockout mice deficient in the 5-HT transporter. Eur J Neurosci 18:2203-2212.

Boutrel B, Monaca C, Hen R, Hamon M, Adrien J (2002) Involvement of 5-HT1A receptors in homeostatic and stress-induced adaptive regulations of paradoxical sleep: studies in 5-HT1A knock-out mice. J Neurosci 22:4686-4692.

Caspi A, Sugden K, Moffitt TE, Taylor A, Craig IW, Harrington H, McClay J, Mill J, Martin J, Braithwaite A, Poulton R (2003) Influence of life stress on depression: moderation by a polymorphism in the 5-HTT gene. Science 301:386-389.
Cowen PJ (2000) Psychopharmacology of 5-HT(1A) receptors. Nucl Med Biol 27:437-439.

Dugovic C, Maccari S, Weibel L, Turek FW, Van Reeth O (1999) High corticosterone levels in prenatally stressed rats predict persistent paradoxical sleep alterations. J Neurosci 19:8656-8664.

Duverneuil C, de la Grandmaison GL, de Mazancourt P, Alvarez JC (2003) A high-performance liquid chromatography method with photodiodearray UV detection for therapeutic drug monitoring of the nontricyclic antidepressant drugs. Ther Drug Monit 25:565-573.

El Yacoubi M, Bouali S, Popa D, Naudon L, Leroux-Nicollet I, Hamon M, Costentin J, Adrien J, Vaugeois JM (2003) Behavioral, neurochemical, and electrophysiological characterization of a genetic mouse model of depression. Proc Natl Acad Sci USA 100:6227-6232.

Evrard A, Malagie I, Laporte AM, Boni C, Hanoun N, Trillat AC, Seif I, De Maeyer E, Gardier A, Hamon M, Adrien J (2002) Altered regulation of the 5-HT system in the brain of MAO-A knock-out mice. Eur J Neurosci 15:841-851.

Fabre V, Beaufour C, Evrard A, Rioux A, Hanoun N, Lesch KP, Murphy DL, Lanfumey L, Hamon M, Martres MP (2000) Altered expression and functions of serotonin 5-HT1A and 5-HT1B receptors in knock-out mice lacking the 5-HT transporter. Eur J Neurosci 12:2299-2310.

Fava M, Kendler KS (2000) Major depressive disorder. Neuron 28:335-341. Frank MG, Heller HC (1997) Neonatal treatments with the serotonin uptake inhibitors clomipramine and zimelidine, but not the noradrenaline uptake inhibitor desipramine, disrupt sleep patterns in adult rats. Brain Res 768:287-293.

Fuller KH, Waters WF, Binks PG, Anderson T (1997) Generalized anxiety and sleep architecture: a polysomnographic investigation. Sleep 20:370-376.

Gaspar P, Cases O, Maroteaux L (2003) The developmental role of serotonin: news from mouse molecular genetics. Nat Rev Neurosci 4:1002-1012.

Geczy J, Bruhwyler J, Scuvee-Moreau J, Seutin V, Masset H, Van Heugen JC, Dresse A, Lejeune C, Decamp E, Szente L, Szejtli J, Liegeois JF (2000) The inclusion of fluoxetine into gamma-cyclodextrin increases its bioavailability: behavioral, electrophysiological and pharmacokinetic studies. Psychopharmacology (Berl) 151:328-334.

Gillespie CF, Nemeroff CB (2005) Hypercortisolemia and depression. Psychosom Med 67 [Suppl 1]:S26-S28.

Goodwin GM, De Souza RJ, Green AR (1985) The pharmacology of the hypothermic response in mice to 8-hydroxy-2-(di-npropylamino)tetralin (8-OH-DPAT). A model of presynaptic 5-HT1 function. Neuropharmacology 24:1187-1194.

Gross C, Zhuang X, Stark K, Ramboz S, Oosting R, Kirby L, Santarelli L, Beck S, Hen R (2002) Serotonin1A receptor acts during development to establish normal anxiety-like behaviour in the adult. Nature 416:396-400.

Hansen HH, Mikkelsen JD (1998) Long-term effects on serotonin transporter mRNA expression of chronic neonatal exposure to a serotonin reuptake inhibitor. Eur J Pharmacol 352:307-315.

Hansen HH, Sanchez C, Meier E (1997) Neonatal administration of the selective serotonin reuptake inhibitor $\mathrm{Lu}$ 10-134-C increases forced swimming-induced immobility in adult rats: a putative animal model of depression? J Pharmacol Exp Ther 283:1333-1341.

Hariri AR, Holmes A (2006) Genetics of emotional regulation: the role of the serotonin transporter in neural function. Trends Cogn Sci 10:182-191.

Hasler G, Drevets WC, Manji HK, Charney DS (2004) Discovering endophenotypes for major depression. Neuropsychopharmacology 29:1765-1781.

Hilakivi LA, Hilakivi I (1987) Increased adult behavioral "despair" in rats neonatally exposed to desipramine or zimeldine: an animal model of depression? Pharmacol Biochem Behav 28:367-369.

Holmes A, Yang RJ, Murphy DL, Crawley JN (2002) Evaluation of antidepressant-related behavioral responses in mice lacking the serotonin transporter. Neuropsychopharmacology 27:914-923.

Holmes A, Murphy DL, Crawley JN (2003a) Abnormal behavioral phenotypes of serotonin transporter knockout mice: parallels with human anxiety and depression. Biol Psychiatry 54:953-959.

Holmes A, Lit Q, Murphy DL, Gold E, Crawley JN (2003b) Abnormal anxiety-related behavior in serotonin transporter null mutant mice: the influence of genetic background. Genes Brain Behav 2:365-380.

Ishiwata H, Shiga T, Okado N (2005) Selective serotonin reuptake inhibitor 
treatment of early postnatal mice reverses their prenatal stress-induced brain dysfunction. Neuroscience 133:893-901.

Kalueff AV, Gallagher PS, Murphy DL (2006) Are serotonin transporter knockout mice "depressed"? Hypoactivity but no anhedonia. NeuroReport 17:1347-1351.

Kornstein SG, Schatzberg AF, Thase ME, Yonkers KA, McCullough JP, Keitner GI, Gelenberg AJ, Ryan CE, Hess AL, Harrison W, Davis SM, Keller MB (2000) Gender differences in chronic major and double depression. J Affect Disord 60:1-11.

Kugelberg FC, Carlsson B, Ahlner J, Bengtsson F (2003) Stereoselective single-dose kinetics of citalopram and its metabolites in rats. Chirality 15:622-629.

Ladd CO, Huot RL, Thrivikraman KV, Nemeroff CB, Plotsky PM (2004) Long-term adaptations in glucocorticoid receptor and mineralocorticoid receptor mRNA and negative feedback on the hypothalamo-pituitaryadrenal axis following neonatal maternal separation. Biol Psychiatry 55:367-375.

Lattimore KA, Donn SM, Kaciroti N, Kemper AR, Neal Jr CR, Vazquez DM (2005) Selective serotonin reuptake inhibitor (SSRI) use during pregnancy and effects on the fetus and newborn: a meta-analysis. J Perinatol 25:595-604.

Lena C, Popa D, Grailhe R, Escourrou P, Changeux JP, Adrien J (2004) $\beta 2$-Containing nicotinic receptors contribute to the organization of sleep and regulate putative micro-arousals in mice. J Neurosci 24:5711-5718.

Levinson DF (2006) The genetics of depression: a review. Biol Psychiatry 60:84-92.

Li Q, Holmes A, Ma L, Van de Kar LD, Garcia F, Murphy DL (2004) Medial hypothalamic 5-hydroxytryptamine (5-HT)1A receptors regulate neuroendocrine responses to stress and exploratory locomotor activity: application of recombinant adenovirus containing 5-HT1A sequences. J Neurosci 24:10868-10877.

Lira A, Zhou M, Castanon N, Ansorge MS, Gordon JA, Francis JH, BradleyMoore M, Lira J, Underwood MD, Arango V, Kung HF, Hofer MA, Hen R, Gingrich JA (2003) Altered depression-related behaviors and functional changes in the dorsal raphe nucleus of serotonin transporterdeficient mice. Biol Psychiatry 54:960-971.

Lister RG (1987) The use of a plus-maze to measure anxiety in the mouse. Psychopharmacology (Berl) 92:180-185.

Maciag D, Simpson KL, Coppinger D, Lu Y, Wang Y, Lin RC, Paul IA (2006a) Neonatal antidepressant exposure has lasting effects on behavior and serotonin circuitry. Neuropsychopharmacology 31:47-57.

Maciag D, Williams L, Coppinger D, Paul IA (2006b) Neonatal citalopram exposure produces lasting changes in behavior which are reversed by adult imipramine treatment. Eur J Pharmacol 532:265-269.

Marinesco S, Bonnet C, Cespuglio R (1999) Influence of stress duration on the sleep rebound induced by immobilization in the rat: a possible role for corticosterone. Neuroscience 92:921-933.

Mirmiran M, van de Poll NE, Corner MA, van Oyen HG, Bour HL (1981) Suppression of active sleep by chronic treatment with chlorimipramine during early postnatal development: effects upon adult sleep and behavior in the rat. Brain Res 204:129-146.

Monaca C, Boutrel B, Hen R, Hamon M, Adrien J (2003) 5-HT 1A/1B receptor-mediated effects of the selective serotonin reuptake inhibitor, citalopram, on sleep: studies in 5-HT 1A and 5-HT 1B knockout mice. Neuropsychopharmacology 28:850-856.

Murphy DL, Lesch KP (2008) Targeting the murine serotonin transporter: insights into human neurobiology. Nat Rev Neurosci 9:85-96.

Nestler EJ, Gould E, Manji H, Buncan M, Duman RS, Greshenfeld HK, Hen R, Koester S, Lederhendler I, Meaney M, Robbins T, Winsky L, Zalcman S (2002) Preclinical models: status of basic research in depression. Biol Psychiatry 52:503-528.
Overstreet DH (2002) Behavioral characteristics of rat lines selected for differential hypothermic responses to cholinergic or serotonergic agonists. Behav Genet 32:335-348.

Owens MJ, Knight DL, Nemeroff CB (2001) Second-generation SSRIs: human monoamine transporter binding profile of escitalopram and R-fluoxetine. Biol Psychiatry 50:345-350.

Pineyro G, Blier P (1999) Autoregulation of serotonin neurons: role in antidepressant drug action. Pharmacol Rev 51:533-591.

Popa D, Lena C, Fabre V, Prenat C, Gingrich J, Escourrou P, Hamon M, Adrien J (2005) Contribution of 5- $\mathrm{HT}_{2}$ receptor subtypes to sleepwakefulness and respiratory control, and functional adaptations in knock-out mice lacking 5- $\mathrm{HT}_{2 \mathrm{~A}}$ receptors. J Neurosci 25:11231-11238.

Popa D, El Yacoubi M, Vaugeois JM, Hamon M, Adrien J (2006) Homeostatic regulation of sleep in a genetic model of depression in the mouse: effects of muscarinic and 5-HT1A receptor activation. Neuropsychopharmacology 31:1637-1646.

Porsolt RD, Le Pichon M, Jalfre M (1977) Depression: a new animal model sensitive to antidepressant treatments. Nature 266:730-732.

Porsolt RD, Anton G, Blavet N, Jalfre M (1978) Behavioural despair in rats: a new model sensitive to antidepressant treatments. Eur J Pharmacol 47:379-391.

Prathiba J, Kumar KB, Karanth KS (1998) Hyperactivity of hypothalamic pituitary axis in neonatal clomipramine model of depression. J Neural Transm 105:1335-1339.

Sapolsky RM, Krey LC, McEwen BS (1984) Glucocorticoid-sensitive hippocampal neurons are involved in terminating the adrenocortical stress response. Proc Natl Acad Sci USA 81:6174-6177.

Shiromani PJ, Overstreet D, Levy D, Goodrich CA, Campbell SS, Gillin JC (1988) Increased REM sleep in rats selectively bred for cholinergic hyperactivity. Neuropsychopharmacology 1:127-133.

Steru L, Chermat R, Thierry B, Simon P (1985) The tail suspension test: a new method for screening antidepressants in mice. Psychopharmacology (Berl) 85:367-370.

Stockmeier CA, Shapiro LA, Dilley GE, Kolli TN, Friedman L, Rajkowska G (1998) Increase in serotonin-1A autoreceptors in the midbrain of suicide victims with major depression-postmortem evidence for decreased serotonin activity. J Neurosci 18:7394-7401.

Ursin R (2002) Serotonin and sleep. Sleep Med Rev 6:55-69.

Velazquez-Moctezuma J, Diaz Ruiz O (1992) Neonatal treatment with clomipramine increased immobility in the forced swim test: an attribute of animal models of depression. Pharmacol Biochem Behav 42:737-739.

Vogel G, Neill D, Hagler M, Kors D (1990a) A new animal model of endogenous depression: a summary of present findings. Neurosci Biobehav Rev 14:85-91.

Vogel GW, Buffenstein A, Minter K, Hennessey A (1990b) Drug effects on REM sleep and on endogenous depression. Neurosci Biobehav Rev 14:49-63.

Wellman CL, Izquierdo A, Garrett JE, Martin KP, Carroll J, Millstein R, Lesch KP, Murphy DL, Holmes A (2007) Impaired stress-coping and fear extinction and abnormal corticolimbic morphology in serotonin transporter knock-out mice. J Neurosci 27:684-691.

Willner P (2005) Chronic mild stress (CMS) revisited: consistency and behavioural-neurobiological concordance in the effects of CMS. Neuropsychobiology 52:90-110.

Wisor JP, Wurts SW, Hall FS, Lesch KP, Murphy DL, Uhl GR, Edgar DM (2003) Altered rapid eye movement sleep timing in serotonin transporter knockout mice. NeuroReport 14:233-238.

Zhao S, Edwards J, Carroll J, Wiedholz L, Millstein RA, Jaing C, Murphy DL, Lanthorn TH, Holmes A (2006) Insertion mutation at the C-terminus of the serotonin transporter disrupts brain serotonin function and emotion-related behaviors in mice. Neuroscience 140:321-334. 